\title{
IMPLANTAÇÃO DE BANCO FORRAGEIRO COM LEGUMINOSA HERBÁCEA EM UNIDADE DE PRODUÇÃO FAMILIAR
}

\author{
Dayanne Lustosa Mororó $^{1}$; Luis Moreira de Araujo Junior ${ }^{2}$; Alzira Gabriela da Silva Pause ${ }^{3}$; \\ Rosana Quaresma Maneschy ${ }^{4}$ \\ ${ }^{1}$ Discente do curso de Agronomia, Faculdade de Ciências Agrárias de Marabá (FCAM), Universidade Federal do Pará \\ (UFPA) bolsista PIBEX-PROEX, dayanne_mba@ hotmail.com \\ ${ }^{2}$ Discente do curso de Agronomia, FCAM, UFPA, bolsistas PIBEX-PROEX, luismoreirajr@ hotmail.com \\ ${ }^{3}$ Zootecnista. D.Sc., FCAM, UFPA, alziragabi@ufpa.br \\ ${ }^{4}$ Engenheira Agrônoma, D.Sc., FCAM, UFPA, romaneschy@ufpa.br
}

\begin{abstract}
RESUMO: A utilização de bancos forrageiros de leguminosas e gramíneas apresenta-se como uma eficiente alternativa para a minimização do déficit alimentar no período seco, o que pode manter e/ou aumentar a produção leiteira. Conduziu-se este trabalho com o objetivo de implantar banco forrageiro de leguminosa com gramínea para complementação alimentar das vacas em lactação no período seco do ano no projeto de assentamento (P. A.) Belo Horizonte, São Domingos do Araguaia-Pará. Na implantação do banco forrageiro, a família escolheu a área e as espécies a serem utilizadas. Assim, o estilosantes cv. Campo Grande (Stylosanthe capitata $x$ Stylosanthes macrocephala) foi semeado no mês de março de 2009, a lanço na superfície do solo das entrelinhas de milheto forrageiro (Pennisetum glaucum (L.) R. Brown), com uma taxa de semeadura de 2 a 3,5 $\mathrm{kg} \cdot \mathrm{ha}^{-1}$ de sementes puras viáveis (SPV), em uma área de $400 \mathrm{~m}^{2}$. O banco de proteína de estilosantes só nasceu no segundo ano depois de semeado. A semeadura silmutânea da leguminosa e gramínea prejudicou o estabelecimento do estilosantes. Posteriormente à implantação do banco de proteína com estilosantes, o mesmo foi submetido ao pastejo de bovinos. As vacas pastejaram por um período de duas horas diariamente na área do banco forrageiro, após a ordenha matinal. A implantação do banco forrageiro com estilosantes Campo Grande ocorreu somente dois anos após a sua semeadura, portanto a utilização do banco para o pastejo de vacas em lactação foi efetuado com sucesso no período seco do ano de 2010.
\end{abstract}

PALAVRAS-CHAVE: Agricultura familiar, estilosantes, produção leiteira.

\section{APLICACIÓN DEL BANCO CON LEGUMINOSAS FORRAJERAS EN FAMILIA HERBÁCEOS UNIDAD DE PRODUCCIÓN}

RESUMEN: El uso de bancos de forraje de leguminosas y gramíneas se presenta como una alternativa eficaz a la minimización de la escasez de alimentos durante la estación seca, que puede mantener y / o aumento de la producción de leche. Hemos realizado este estudio con el objetivo de implementar la base de datos de leguminosas forrajeras con la hierba para la suplementación alimentaria de vacas en la estación seca en el proyecto de asentamiento (AP), Belo Horizonte, São Domingos do Araguaia, Pará. Implementación del banco de forraje, la familia optó por la zona y las especies a utilizar. Por lo tanto, el stylosanthes cv. Campo Grande (Stylosanthes macrocephala $\mathrm{x}$ Stylosanthes capitata) se sembró en marzo de 2009, emitido en la superficie del suelo entre las hileras de forraje de Pennisetum glaucum (L.) R. Brown, con una densidad de siembra de 2-3,5 kg ha-1 de semillas puras viables (SPV), en una superficie de $400 \mathrm{~m}^{2}$. El banco de proteínas con 
estilosantes solamente tuve producción en el segundo año después de la siembra. La siembra de la leguminosa y la hierba simultánea obstaculizado el establecimiento de stylosanthes. Después de la implantación de un banco de proteína con Estilo, se ha sometido a pastoreo de ganado. Las vacas pastaban por un período de dos horas diarias en el área de banco de forraje después del ordeño de la mañana. La implantación del banco forrajero con stylosanthes cv. Campo Grande se produjo sólo dos años después de la siembra, lo que el uso del banco para las vacas lecheras en pastoreo tuvo éxito en el año seco de 2010.

PALABRAS CLAVES: Agricultura familiar, stylosanthes, producción de leche.

\section{INTRODUÇÃO}

A agricultura familiar pode ser conceituada como um modelo de organização da produção agropecuária onde predominam a interação entre a gestão e o trabalho, a direção do processo produtivo pelos proprietários e o trabalho familiar complementado pelo trabalho assalariado (NEVES, 2007).

Nas regiões Sul e Sudeste do Estado do Pará há uma grande concentração de propriedades familiares, alocadas principalmente nos diversos projetos de assentamentos (P. A.), que de acordo com o Instituto Nacional de Colonização e Reforma Agrária (BRASIL, 2009) totalizam 482 P. A. com aproximadamente 67.013 famílias.

A atividade pecuária exercida por esses produtores é quase que totalmente a bovinocultura leiteira, a qual garante renda através da comercialização do leite ou de seus subprodutos em parte do ano, visto que, no período seco ocorre perda de peso dos animais e redução acentuada na produção de leite (COSTA, 2005). Essa redução da produção de leite ocorre em função do déficit alimentar das vacas em lactação no período crítico do ano, pois as pastagens é praticamente a única fonte de alimentação dos rebanhos.

O estilosante Campo Grande é uma leguminosa originada a partir do cruzamento entre o Stylosanthes capitata e $S$. macrocephala. É uma forrageira rica em proteína e executa uma função importante de transformar o nitrogênio encontrado na atmosfera e fixá-lo biologicamente no solo. Assim, reduz os investimentos em insumos agrícolas e contribui para a redução dos impactos ambientais.

O estilosante Campo Grande apresenta grande adaptação a solos arenosos e de baixa fertilidade; boa capacidade de persistência em consorciação com gramínea; boa digestibilidade, e maior ganho de peso nos animais (GARCIA et al., 2008).

Neste contexto, a utilização de bancos forrageiros de gramíneas e leguminosas apresenta-se como uma eficiente alternativa 
para a minimização do déficit alimentar no período seco, o que pode manter e/ou aumentar a produção leiteira.

Foi conduzida uma ação-teste com objetivo de implantar banco forrageiro de gramínea com leguminosa para ser fornecida às vacas em lactação no período seco do ano no projeto de assentamento Belo Horizonte, São Domingos do Araguaia-Pará.

\section{MATERIAL E MÉTODOS}

A atividade extensionista foi uma ação do projeto "Introdução de bancos forrageiros de alta qualidade e da prática de confecção de silagem de gramíneas e/ou leguminosas no projeto de assentamento Belo Horizonte, São Domingos do Araguaia-Pará". O projeto de assentamento Belo Horizonte (PABH) possui 70 famílias e está situado no km 30 da BR153, no município de São Domingos do Araguaia, Pará, pontuado geograficamente pelas coordenadas $5^{\circ} 47^{\prime} 15,4^{\prime}$ 'S e $48^{\circ} 39^{\prime}$ 26,9" W. O clima regional segundo KOPPEN (1948) é do tipo Am no limite de transição para Aw com temperatura média anual de $26,3^{\circ} \mathrm{C}$, caracterizado por um período menos chuvoso entre os meses de maio a outubro e um período mais chuvoso entre os meses de novembro a abril.

Foi utilizada a metodologia de pesquisaação com abordagem participativa (FRAPPAT et al., 2005), com a finalidade de construir inovações em parcerias com agricultores através de ações testes em meio real (CHIA et al., 2006). Considera-se como ação-teste, quando guiado por um facilitador, os agricultores realizam um pequeno ensaio teste, em parcelas pequenas, as quais podem ter diferentes tratamentos (CIAT, 1993).

O início das atividades se deram por meio de uma reunião no mês março de 2009. Foram apresentadas diferentes alternativas para os agricultores de forrageiras entre gramíneas e leguminosas, para a implantação do banco, como amendoim forrageiro (Arachis pintoi), feijão guandú (Cajanus cajan), calopogônio (Calopogonium mucunoides), puerária (Pueraria phaseoloides), leucena (Leucaena leucocephala), estilosantes (Stylosanthes spp.) e cratylia (Cratylia argentea); e gramíneas como o milheto (Pennisetum glaucum) e o sorgo (Sorghum bicolor). O grupo deveria escolher qual família conduziria a ação-teste em seu lote, e a mesma escolheria o local a ser implantada a ação e a(s) espécies para compor o banco forrageiro.

\section{RESULTADOS E DISCUSSÃO}

Trinta famílias de agricultores participaram da reunião de apresentação das alternativas de bancos forrageiros, e a partir 
de critérios definidos pelas próprias famílias, uma foi escolhida para desenvolver a açãoteste em seu lote. Os critérios determinados segundo a ordem de importância foram: interesse na temática, disponibilidade de área para a implantação, disponibilidade de mão de obra para as atividades de preparo de área, plantio e tratos culturais necessários, e comprometimento com a parceria.

O local escolhido foi o estabelecimento "Betelno" e as espécies escolhidas pela família foram a leguminosa estilosantes cv. Campo Grande (Stylosanthe capitata $x$ Stylosanthes macrocephala), que tem sementes disponíveis no mercado local e o milheto forrageiro (Pennisetum glaucum (L.) R. Brown) com a intenção de produzir silagem. Ambas as espécies ainda não tinham sido utilizadas pelas famílias para essas finalidades. Apesar da família ter escolhido a área, a equipe de facilitadores visitou a mesma a fim de verificar as condições locais disponíveis para a implantação da ação-teste com banco forrageiro de leguminosa $\mathrm{e}$ gramínea escolhida pela família. Segundo Camarão; Azevedo (2005) para a formação do banco de proteína a leguminosa deve ser adaptada às condições edafoclimáticas locais, tolerante à seca, ter elevado teor protéico, produzir forragem satisfatoriamente, ter boa recuperação pós-pastejo e, principalmente, ser bem consumida pelos animais, de forma a complementar as deficiências dos animais mantidos em pastagem tradicionais.

O plantio foi realizado no mês de março de 2009, época adequada segundo a literatura, que recomenda que o banco de proteína deve ser plantado no período chuvoso (CAMARÃO; AZEVEDO, 2005). estilosantes cv. Campo Grande foi semeado a lanço na superfície do solo das entrelinhas de milheto forrageiro (Pennisetum glaucum (L.) R. Brown) com uma taxa de semeadura de 2 a 3,5 kg.ha-1 de sementes puras viáveis (SPV), em uma área de $400 \mathrm{~m}^{2}$.

O banco de proteína de estilosantes só nasceu no segundo ano depois de semeado. Atribui-se a isto a não redução em 30\% a 40\% da taxa de semeadura da gramínea que foi consorciada para possibilitar o estabelecimento da leguminosa e ainda a forma de semeadura, a qual foi em superfície, que segundo Embrapa (2007), este método não confere bom estabelecimento da leguminosa. Outro fator a ser considerado no baixo desenvolvimento inicial da leguminosa foi à concorrência entre a leguminosa e as gramíneas presentes no local, uma vez que normalmente, o estabelecimento das leguminosas é mais lento do que das gramíneas, o que exige uma limpeza (CAMARÃO; AZEVEDO, 2005), fato este que não ocorreu frequentemente em função da falta de mão de obra necessária para a 
execução dessas atividades. Uma vez que, no momento do estabelecimento do banco forrageiro a família responsável pela ação teste, teve problemas de saúde, o que exigiu a venda de mão-de-obra de alguns membros da família para suprir as necessidades financeiras. E a pouca mão-de-obra disponível foi atribuída a outras atividades de maior importância para a família.

O estilosantes é uma forrageira rica em proteína e executa uma função importante de transformar o nitrogênio encontrado na atmosfera e fixá-lo biologicamente no solo. Assim, reduz os investimentos em insumos agrícolas, o que contribui para a redução dos impactos ambientais (GARCIA et al., 2008). $\mathrm{O}$ que resulta em uma boa aceitação pelos agricultores, uma vez que diminui o custo na manutenção das pastagens e utilização de sais e proteinados.

No segundo ano após a implantação vacas em lactação iniciaram o pastejo no banco forrageiro, durante o período seco, por duas horas diariamente após a ordenha matinal. Os agricultores relataram boa aceitabilidade dos animais no pastejo com o estilosantes. Segundo Faichney (1986), o consumo do pasto selecionado pelos ruminantes é influenciado pela taxa em que é degradado no rúmen e pela taxa de remoção dos resíduos não digeridos do rúmen-retículo.
Durante o período seco do ano o valor nutritivo das forrageiras comumente utilizadas na região amazônica decresce, como por exemplo, pode-se citar o caso do braquiarão (Brachiaria humidicola cv. Marandú) no estado do Pará (BITTENCOURT; VEIGA, 2001; MANESCHY et al. 2005), e que é utilizado para pastejo nesse lote. Quando os animais são alimentados com forragens de baixo valor nutritivo, menor taxa de passagem das partículas do rúmen é verificada, o que acarreta em redução no consumo de matéria seca (VAN SOEST, 1994). Assim, recomendam-se avaliações futuras sobre o manejo do banco forrageiro e seu efeito na produção leiteira, bem como da qualidade nutricional das forrageiras utilizadas pelos agricultores e as sugeridas nessa ação extensionista a fim de contribuir com o desenvolvimento da pecuária praticada por agricultores familiares na região sudeste do Pará.

\section{CONCLUSÕES}

A implantação do banco forrageiro com estilosantes Campo Grande ocorreu somente dois anos após a sua semeadura, portanto a utilização do banco para o pastejo de vacas em lactação foi efetuado com sucesso no período seco do ano de 2010. 


\section{REFERÊNCIAS}

BITTENCOURT, P. C. S.; VEIGA, J. B. Avaliação das pastagens de Brachiaria brizantha cv. Marandu em propriedades leiteiras de Uruará, região da Transamazônica, Pará, Brasil. Pasturas Tropicales, Cali, Colômbia, v. 23, n. 2, p. 2-9, 2001.

BRASIL. Instituto Nacional de Colonização e Reforma Agrária - INCRA. Superintendência Regional do Sul do Pará - SR(27). Ordem de Serviço/SR-(27)G/No 01-11, de 02 de janeiro de 2009. Diário Oficial da União, Brasília, 20 de outubro de 2006; $264^{\circ}$.

CAMARÃO, A. P.; AZEVEDO, G. P. C. Formação e utilização de banco de proteína Sistemas de Produção. Criação de Gado Leiteiro na Zona Bragantina, Embrapa Amazônia Oriental, Dez./2005.

CHIA, E.; DUGUÉ, P.; SAKHO-JIMBIRA, S. Les exploitations agricoles familiales sontelles des institutions? Agricultures, Montpellier, v. 15, n. 6, 2006, 498-505 p.

CIAT. Centro Internacional de Agricultura Tropical. Cartillas para CIAL (Comités de Investigación Agrícola Local: $\mathrm{O}$ ensayo. Cali: CIAT/IPRA, 1993. 43 p.

COSTA, N. L. Redução de Queimadas em Pastagens da Amazônia Ocidental. Bancosde Proteína. 2005. Disponível em: <http://www. agrolink. com. br / colunistas / pg_detalhe_coluna.asp $>$. Acesso em: 11 outubro 2010.

EMBRAPA. Cultivo e uso dos estilosantescampo-grande.Comunicado Técnico no 105. Campo Grande,MS. 2007. 11 p. Disponível em:

$<$ http://www.cnpgc.embrapa.br/publicacoes/c ot/pdf/Cot105.pdf $>$. Acesso em: 18 outubro 2010

FAICHNEY, G. J. The kinetics of particulate matter in the rumen. In: MILLIGAN, L.P.;
GROVUM, W.L; DOBSON, A. (Eds.) Control of digestion and metabolism in ruminants. INTERNACIONAL SYMPOSIUM ON RUMINANT PHYSIOLOGY, 6., 1984, Canada. Proceedings... Englewood Cliffs: PrenticeHall, 1986. p. 173-195.

FRAPPAT, B.; DOCKES, A. C.; SOUQUET, C.; LACOUR, C. Les attentes et besoins des éleveurs de bovins en matière de conseil.

Actes des Rencontres recherches

Ruminants. Paris, 2005, 5p.

GARCIA, F. M., BARBOSA, R. Z., GIATTI JR., N. O. O USO DE ESTILOSANTES CAMPO GRANDE EM CONSÓRCIO COM BRAQUIARINHA (Brachiaria decumbens). Revista Científica Eletrônica de Agronomia, v. 7, n. 13, 2008 - Periódicos Semestral. Disponível em: $<$ http://www.revista.inf.br/agro13/artigos/Ano VII-Edic13-Art07.pdf >. Acesso em: 14 outubro 2010

KÖPPEN, W. Climatologia Tradicional. Traduzido para o Espanhol por Pedro Henchiehs Pérez, 1948.

MANESCHY, R. Q.; CARDOSO, E. da C.; VEIGA, J. B.; MCDOWELL, L. R. Effect of season on mineral concentrations of Braquiaria (Brachiaria brizantha cv. Marandu) in dairy cattle farms of Eastern Amazon. I. Macrominerals. Journal of Animal and Veterinary Advances, USA, v. 4, n. 1, p. 118-122, 2005.

NEVES, D. P. Agricultura Familiar: quantos ancoradouros! In: FERNANDES, B. M.; MARQUES, M. I. M.; SUZUKI, J. C. (org.) Geografia Agrária: teoria e poder. $1^{\mathrm{a}}$ ed. São Paulo: Expressão Popular, 2007, v. 1, p. 21170.

SILVA, J. J.; SALIBA, E. O. S. Pastagens consorciadas: Uma alternativa para sistemas 
extensivos e orgânicos. Veterinária e

Zootecnia. v.14, n.1, jun., p. 8-18, 2007.

VAN SOEST, P. J. Nutritional ecology of the ruminant. Ithaca: Cornell University Press, 1994. 470p.

\section{AGRADECIMENTOS}

O presente trabalho foi realizado com o apoio da Pró-Reitoria de Extensão - PROEX da Universidade Federal do Pará - UFPA. 